Agnieszka Czajkowska ${ }^{1}$

\title{
WYKORZYSTANIE DIAGRAMU PARETO - LORENZA DO ANALIZY PRZYCZYN KATASTROF BUDOWLANYCH SPOWODOWANYCH BLĘDAMI LUDZKIMI Z UWZGLĘDNIENIEM CYKLU ŻYCIA OBIEKTU BUDOWLANEGO W LATACH 2013-2017
}

\begin{abstract}
Streszczenie: W artykule przeanalizowano przyczyny katastrof budowlanych w latach 2013-2017. $\mathrm{W}$ prowadzonej analizie przyczyny wystąpienia katastrof budowlanych powiązano $\mathrm{z}$ cyklem życia obiektu budowlanego. Szczególną uwagę poświęcono błędom ludzkim wpływającym na wystąpienie katastrof budowlanych. Do identyfikacji najczęstszych błędów skutkujących wystąpieniem katastrof budowlanych zastosowano diagram Pareto-Lorenza. Z przeprowadzonej analizy wynika, że dwa błędy przyczyniają się do wystąpienia $75 \%$ wszystkich katastrof. Błędy te należą do dwóch spośród pięciu głównych faz cyklu życia obiektu budowlanego - utrzymania obiektu budowlanego oraz prowadzenia robót $\mathrm{w}$ istniejącym obiekcie.
\end{abstract}

Słowa kluczowe: katastrofy budowlane, cykl życia obiektu budowlanego, diagram Pareto-Lorenza

\section{Wprowadzenie}

Katastrofą budowlaną jest ,niezamierzone, gwałtowne zniszczenie obiektu budowlanego lub jego części, a także konstrukcyjnych elementów rusztowań, elementów formujacych, ścianek szczelnych i obudowy wykopów” [1-3]. Katastrofy budowlane podlegają rejestracji od 1995 roku. W systemie elektronicznym rejestrowane są od 2008 roku. W rejestrze znajdują się informacje o katastrofach budowlanych wprowadzone przez powiatowych i wojewódzkich inspektorów nadzoru budowlanego $\mathrm{w}$ ramach zadań i kompetencji określonych $\mathrm{w}$ art. 76 ust. 1 pkt 2 ustawy - Prawo budowlane.

Najczęstszą przyczyna katastrof budowlanych są zdarzenia losowe wynikające z warunków atmosferycznych jak silne, porywiste wiatry, często wraz z intensywnymi opadami i wyładowaniami atmosferycznymi oraz pożary.

Główny Urząd Nadzoru Budowlanego prowadzi zestawienia liczbowe dotyczące:

- Struktury katastrof na przestrzeni lat,

- Miejsc wystąpienia katastrof wg województw,

\footnotetext{
${ }^{1}$ Kielce University of Technology, a_czajkowska@o2.pl, ORCID ID: 0000-0002-7430-4758
} 
- Rodzajów obiektów budowlanych z podziałem na:

- budynki gospodarcze lub inwentarskie,

- budynki mieszkalne,-obiekty przemysłowe -18 (2,9\% wszystkich katastrof),

- obiekty użyteczności publicznej,

- budynki magazynowe,

- budynki rekreacji indywidualnej,

- budynki zamieszkania zbiorowego,

- inne budowle.

- Faz życia obiektu budowlanego w tym:

- złego stanu technicznego obiektu budowlanego,

- braku wykonania kontroli obiektu budowlanego,

- braku podjęcia wymaganych działań przez właściciela lub zarządcę wynikających z kontroli obiektu budowlanego,

- braku podjęcia wymaganych działań przez właściciela lub zarządcę wynikających z innych opracowań technicznych,

- użytkowania obiektu budowlanego niezgodnie z jego przeznaczeniem,

- braku wykonania wymaganych obowiązków przez właściciela lub zarządcę wynikających z działań organów nadzoru budowlanego,

- innych okoliczności.

- Błędów podczas budowy nowego obiektu lub wykonywania innych robót budowalnych w istniejącym obiekcie.

- Etapów procesu budowlanego, podczas których wystąpiła katastrofa:

- podczas utrzymania obiektów,

- podczas prowadzenia robót budowlanych.

- Elementów obiektu budowlanego objęte katastrofą:

- pionowe elementy konstrukcyjne budynków,

- konstrukcja dachu budynków,

- konstrukcja stropu budynków,

- elementy obiektów nie będących budynkami (mosty, wiadukty, drogi, wały, zapory, śluzy, jazy i sieci).

- Rodzajów konstrukcji nośnej obiektu ulegającego katastrofie: murowa, drewniana, żelbetowa monolityczna, żelbetowa prefabrykowana, mieszana.

- Czasu eksploatacji obiektu ulegającego katastrofie:

- poniżej 10 lat,

- w przedziale 11-50 lat,

- w przedziale 51-100 lat,

- powyżej 100 lat. 
- Inwestora lub właściciela obiektu ulegającego katastrofie:

- Osoby fizyczne,

- Skarb Państwa,

- Inne podmioty,

- Osób poszkodowanych w katastrofach.

\section{Katastrofy budowlane w latach 2013-2017}

Najwięcej katastrof budowlanych powstaje w wyniku zdarzeń losowych jak. silne wiatry, intensywne opady deszczu lub śniegu, wstrząsy sejsmiczne. Drugą przyczyną jest działalność człowieka, np. wybuch gazu, pożar, wypadek komunikacyjny, w wyniku którego budynek ulegnie zniszczeniu. Trzecią grupę stanowią błędy podczas projektowania, utrzymania oraz rozbiórki. Na rysunku 1 przedstawiono strukturę katastrof budowlanych w latach 2013-2017 z podziałem na katastrofy spowodowane zdarzeniami losowymi oraz te spowodowane przez błędy ludzkie.
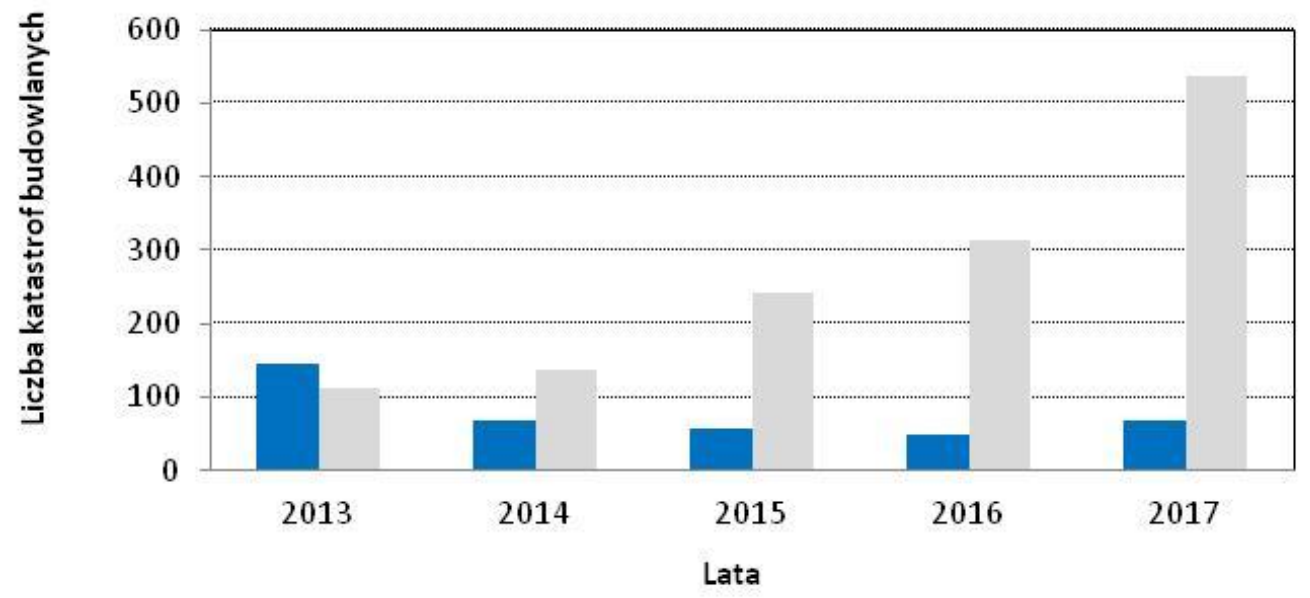

Katastrofy budowlane spowodowane poprzez błędy ludzkie Katastrofy budowlane spowodowane czynnikami losowymi

Rys. 1. Struktura katastrof budowlanych w latach 2013-2017

Źródło: Opracowanie własne na podstawie raportów GUNB

$\mathrm{Z}$ analizy wykresu wynika, że katastrofy spowodowane przez błędy ludzkie stanowią średnio $28 \%$ wszystkich katastrof budowlanych. Są to katastrofy, których można uniknąć lub znacznie ograniczyć ich występowanie. 


\section{Cykl życia obiektu budowlanego z uwzględnieniem najczęstszych błędów popełnianych przez człowieka}

Celem analizy katastrof budowlanych wynikających z błędów popełnianych przez ludzi przeanalizowany został cykl życia obiektu budowlanego (rys. 2). Na cykl życia obiektu budowlanego [4] składa sie pięć głównych etapów:

- Opracowanie dokumentacji obiektu budowlanego,

- Budowa nowego obiektu,

- Utrzymanie obiektu budowlanego,

- Prowadzenie robót $\mathrm{w}$ istniejącym obiekcie,

- Rozbiórka.

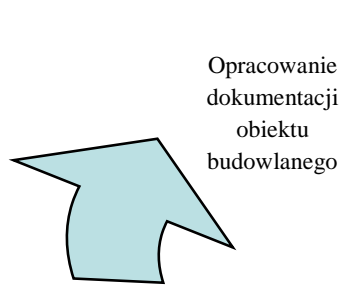

Rozbiórka
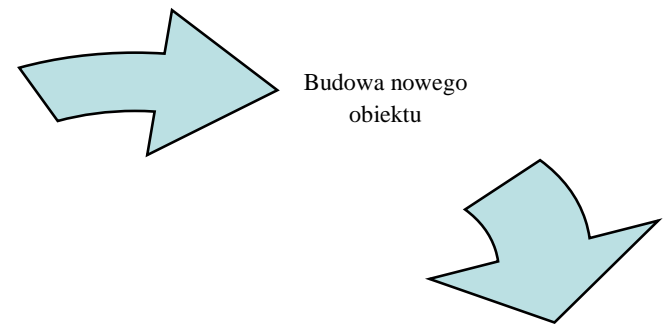

Utrzymanie obiektu budowlanego
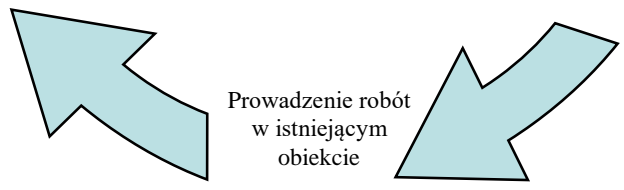

Rys. 2. Fazy cyklu życia obiektu budowlanego.

Źródto: Opracowanie własne

W tabeli 1 zestawiono dane dotyczące błędów ludzkich wynikających raportów Głównego Urzędu Nadzoru Budowlanego za lata 2013-2017. 
Tabela 1. Liczba katastrof budowlanych wg faz cyklu życia obiektu budowlanego za lata 2013-2017

\begin{tabular}{|c|l|c|c|c|c|c|c|}
\hline Symbol & \multicolumn{1}{|c|}{ Rodzaj błędu } & 2017 & 2016 & 2015 & 2014 & 2013 & Razem \\
\hline B1 & $\begin{array}{l}\text { błędy podczas opracowania } \\
\text { dokumentacji obiektu budowlanego }\end{array}$ & 1 & 2 & 23 & 1 & 1 & 28 \\
\hline B2 & $\begin{array}{l}\text { błędy podczas budowy nowego } \\
\text { obiektu }\end{array}$ & 10 & 7 & 6 & 37 & 4 & 64 \\
\hline B3 & $\begin{array}{l}\text { błędy podczas utrzymania obiektu } \\
\text { budowlanego }\end{array}$ & 42 & 39 & 38 & 44 & 70 & 233 \\
\hline B4 & $\begin{array}{l}\text { błędy podczas prowadzenia robót w } \\
\text { istniejącym obiekcie }\end{array}$ & 22 & 10 & 20 & 61 & 11 & 124 \\
\hline B5 & błędy podczas rozbiórki & 5 & 1 & 4 & 11 & 4 & 25 \\
\hline
\end{tabular}

Źródto: opracowanie własne

\section{Zastosowanie diagram Pareto-Lorenza do identyfikacji najczęściej występujących przyczyn katastrof budowlanych związanych $z$ błędami ludzkimi}

Celem prowadzonej analizy jest zmniejszenie przyczyn katastrof budowlanych spowodowanych błędami ludzkimi. Diagram Pareto-Lorenza [5-7] pozwoli wyłonić te przyczyny, które w najwyższym stopniu wpływają na wystąpienie katastrof. Dane liczbowe zestawiono w tabeli 2 natomiast diagram Pareto - Lorenza przedstawiono na rys 3 .

Tabela X. Katastrofy budowlane wg faz cyklu życia obiektu budowlanego w ujęciu procentowym i skumulowanym za lata 2013-2017

\begin{tabular}{|c|c|c|c|}
\hline Symbol błędu & Liczba błędów & Udział procentowy & Udział skumulowany \\
\hline $\mathrm{B}_{3}$ & 233 & 49,16 & 49,16 \\
\hline $\mathrm{B}_{4}$ & 124 & 26,16 & 75,32 \\
\hline $\mathrm{B}_{2}$ & 64 & 13,50 & 88,82 \\
\hline $\mathrm{B}_{1}$ & 28 & 5,91 & 94,73 \\
\hline $\mathrm{B}_{5}$ & 25 & 5,27 & 100,00 \\
\hline Suma & 474 & 100 & $\mathrm{X}$ \\
\hline
\end{tabular}

Źródto: opracowanie własne 


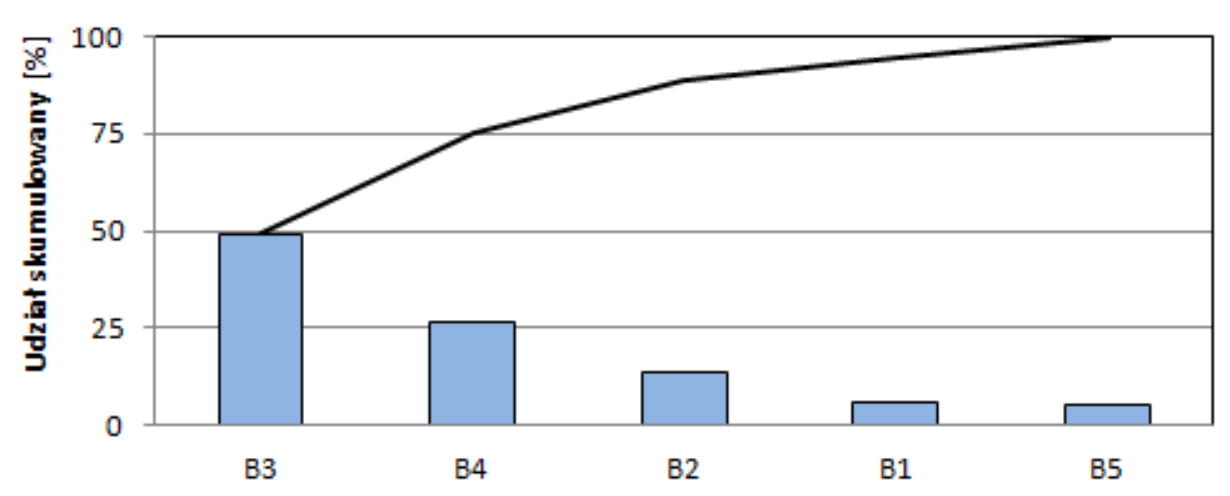

Symbol błędu

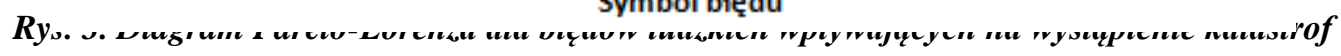
budowlanych w latach 2013-2017

Źródło: opracowanie własne

Z przeprowadzonej analizy wynika, że zgodnie z zasadą diagramu ParetoLorenza dwa błędy odpowiadają za $75 \%$ katastrof budowlanych spowodowanych przez człowieka. Błędy te to B3 - podczas utrzymania obiektu budowlanego oraz B4 podczas prowadzenia robót $\mathrm{W}$ istniejącym obiekcie. Strukturę katastrof budowlanych wynikających z B3 i B4 zaprezentowano na rys. 4.

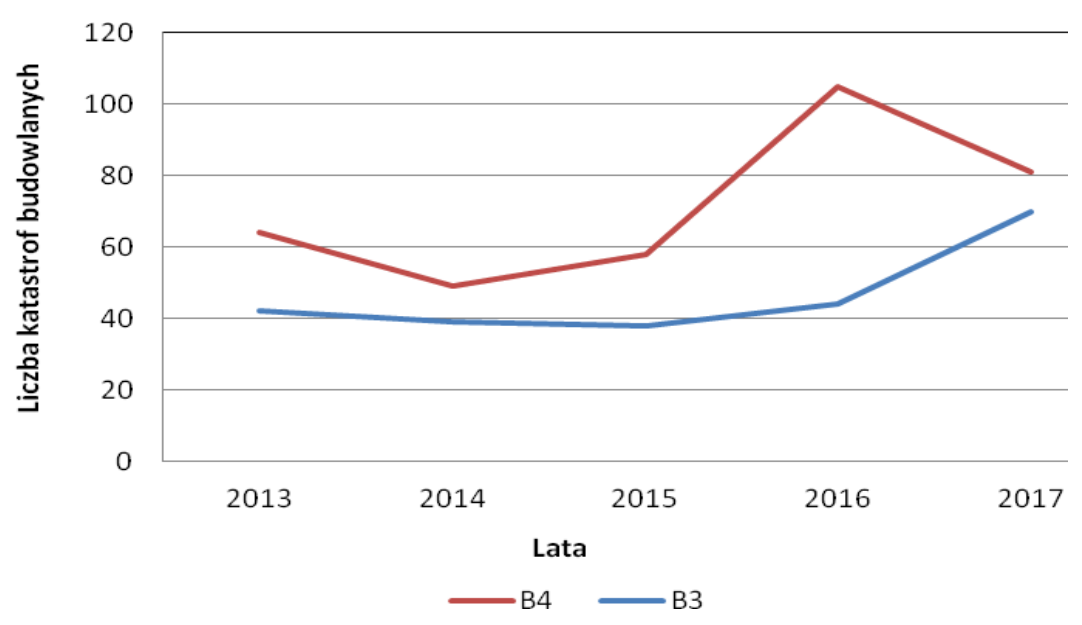

Rys. 4. Najczęstsze blędy (B4, B3) wplywające na wystapienie katastrof budowlanych w latach 2013-2017

Źródto: opracowanie własne 


\section{Podsumowanie}

W artykule przeanalizowano przyczyny katastrof budowlanych w latach 20132017. Szczególną uwagę poświęcono błędom ludzkim wpływającym na wystąpienie katastrof. W analizie wykorzystano diagram Pareto-Lorenza, który pozwolił na identyfikację błędów w największym stopniu wpływających na wystąpienie katastrof budowlanych. Występowanie katastrof powiązano $\mathrm{z}$ fazami cyklu życia obiektu budowlanego od opracowania dokumentacji poprzez budowę, utrzymanie, prowadzenie prac aż po rozbiórkę.

Z przeprowadzonej analizy wynika, że:

- Najwięcej popełnianych błędów jest w trzeciej i czwartej fazie cyklu życia obiektu budowlanego czyli utrzymania obiektu budowlanego oraz prowadzenia robót w obiekcie budowlanym,

- Dwa błędy (B3, B4) stanowią 75\% wszystkich błędów ludzkich skutkujących wystąpieniem katastrofy budowlanej w latach 2013-2017.

\section{Bibliography}

[1] Ustawa z dnia 7 lipca 1994 r. - Prawo Budowlane (Dz.U. z 2010r., Nr 243, poz. 1623 z późn. zm.).

[2] Wierzbicki S. M.: Rola rzeczoznawcy w przypadku zdarzenia się awarii budowlanej. XXV konferencja Naukowo Techniczna Awarie budowlane, 2011.

[3] Czajkowska A.: Analysis of causes of structural failures of buildings using TQC tools. XXIX konferencja Naukowo Techniczna Awarie budowlane, Międzyzdroje, 2019.

[4] Czajkowska A., Ingaldi M.: Aalysis of the impact of individual phases in the building process cycle on the environment with respect to the principles of sustainable development. IOP Conf. Ser.: Earth Environ. Sci. 214 012012, 2017.

[5] Midor K., Žarnovský J.: Innovative use of quality management methods for product improvement. Management Systems in Production Engineering, 2016, pp 264-267, No 4 (24).

[6] Gajdzik B., Sitko J.: An analysis of the causes of complaints about steel sheets in metallurgical product quality management systems. Metalurgija, 2014, vol. 53(1).

[7] Czajkowska A., Stasiak-Betlejewska R.: Determinants of the machining process in the steel industry. 25th Anniversary International Conference on Metallurgy and Materials (METAL 2016), Brno, Czechy (25 - 27 V 2016 r.). 


\title{
THE USE OF THE PARETO-LORENZ DIAGRAM TO ANALYSE THE CAUSES OF STRUCTURAL FAILURES CAUSED BY HUMAN ERRORS WITH REGARD TO THE LIFE CYCLE OF A BUILDING IN THE YEARS 2013-2017
}

\begin{abstract}
The paper reviews the causes of structural failures in 2013-2017. The analysis concerned the links between the causes of structural failures and the life cycle of a building. Particular emphasis was on human errors affecting the occurrence of structural failures. The Pareto-Lorenz diagram was used to identify the most common errors leading to the occurrence of the failures. The analysis showed that two errors contribute to $75 \%$ of all failures. These errors occur in two of the five major phases of the life cycle of a building - maintenance and construction works in the existing building
\end{abstract}

Key words: structural failures, life cycle of a building Pareto - Lorenza diagram.

Data przestania publikacji do Redakcji: 12.03.2018

Data akceptacji publikacji przez Redakcje: 25.05.2019

DOI: 10.30657/qpi.2019.10.05 